\title{
Circuit
}

Musiques contemporaines

\section{Apories du relativisme}

Considérations intempestives... et inactuelles

The uncertainties of relativism

\section{Untimely... and out-of-date considerations}

\section{Jean-Jacques Nattiez}

Volume 6, numéro 2, 1995

Musique actuelle?

URI : https://id.erudit.org/iderudit/902138ar

DOI : https://doi.org/10.7202/902138ar

Aller au sommaire du numéro

Éditeur(s)

Les Presses de l'Université de Montréal

ISSN

1183-1693 (imprimé)

1488-9692 (numérique)

Découvrir la revue

Citer cet article

Nattiez, J.-J. (1995). Apories du relativisme : considérations intempestives... et inactuelles. Circuit, 6(2), 61-66. https://doi.org/10.7202/902138ar
Résumé de l'article

Selon l'auteur, l'attitude des actualistes implique un relativisme de principe par rapport aux notions transcendentales de Vrai, de Bien et de Beau. Prenant l'exemple, douloureux s'il en est, de l'attitude occidentale vis-à-vis de l'excision du clitoris pratiquée en Afrique, il réaffirme la nécessité d'admettre l'existence de jugements de valeur à portée universelle qui débordent les légitimations purement culturelles. 


\section{Apories du relativisme Considérations intempestives... et inactuelles Jean-Jacques Nattiez}

L'émergence du courant dit de la " musique actuelle » est bien symptomatique de l'air du temps. II est d'ailleurs important de souligner que, à chaque époque de l'histoire de la musique, les traits qui caractérisent une attitude compositionnelle et un style musical trouvent leur équivalent dans des idées et des préoccupations qui ne sont pas propres aux domaines esthétiques.

Les théoriciens et les praticiens du modernisme (la musique "contemporaine » d'hier et ses prolongements... actuels !) croient (croyaient) dans le progrès musical, appellent (appellaient) de leur vœu un langage musical universel, recherch(ai)ent une grande homogénéité de style, pratiqu(ai)ent la hiérarchie des valeurs, se prononcent (prononçaient) sur la " nécessité d'une orientation esthétique " ${ }^{\prime \prime)}$ et l'exclusivisme ${ }^{(2)}$, conçoivent (concevaient) essentiellement le langage musical comme un jeu de structures. On trouvera sans peine des équivalents à ces positions dans les domaines culturels et sociopolitiques, et en particulier dans l'idéologie marxiste ou marxisante des années cinquante et soixante, caractérisée par la recherche de l'unitarisme et de la totalité (certains diront: le totalitarisme): croyance dans la perfectibilité humaine et le progrès de la société, projet d'une société universelle et sans classes, élimination des adversaires politiques (trait commun aux révolutionnaires - trotskystes, castristes, maoïstes - et aux staliniens), conception structuraliste des formes symboliques (Lévi-Strauss, Barthes, la Nouvelle Critique) et de la société (Althusser).

A l'inverse, le postmodernisme et l'actualisme ne croient pas plus au progrès humain qu'au progrès esthétique, ils prônent le mélange des genres et des styles, ils pratiquent le métissage et l'hybridation des musiques à l'image d'un monde moderne devenu village global, non pas en raison d'une universalisation sociale et culturelle rêvée dans les années soixante, mais parce que c'est désormais à l'échelle planétaire que circulent et interagissent les êtres, les races et les cultures. Après l'effondrement de l'utopie marxiste et des expériences communistes à vocation universelle, la tendance est au culturalisme - chaque culture a droit à l'existence et son monde de valeurs propres
(1) Titre d'un article important de Pierre Boulez publié en 1964. Publication complète in Boulez (1995), pp. 529-579.

(2) * Tout musicien qui n'a pas ressenti nous ne disons pas compris, mais bien ressenti - la nécessité du langage dodécaphonique est INUTILE. \& (Les majuscules sont de l'auteur.) P. Boulez, \& Éventuellement » (1952), repris in Boulez (1995), p. 265. 
se justifie du fait même de cette existence - et au dialogisme: toutes les cultures du monde ont droit à la coexistence : je dois respecter les valeurs de la culture d'en face, mais elle doit aussi respecter celles de la mienne len principe ...); il n'y a plus de valeurs et de vérité transcendante, transculturelle. Le culturalisme est, à la suite de Geertz, un des fondements de l'anthropologie (et de l'ethnomusicologie) actuelle, le dialogisme fait florès chez les philosophes (Rorty, Vattimo). Bref, à la dictature moderniste, fait suite le relativisme postmoderne qui trouve ses racines épistémologiques chez Derrida: il n'est pas étonnant que le déconstructivisme figure dans l'inventaire inachevé de Joane Hétu.

Le relativisme ambiant s'attaque aux trois grands « transcendentaux » de la spéculation métaphysique traditionnelle : le Bien, le Vrai et le Beau, autrement dit les domaines de l'éthique et de la pratique sociale, de la vérité scientifique et de la valeur esthétique. De ce fait, il ébranle les piliers philosophiques de la tradition occidentale, en particulier le kantisme qui affirmait, entre autres choses, que "le Beau est ce qui plaît universellement sans concept 》 (Kant, 1790, p. 62). Pas étonnant que Pierre Bourdieu, en tentant de démontrer que les jugements esthétiques, en particulier à propos de l'art moderne, s'expliquent non par référence à des catégories intangibles, mais comme pur produit de l'appartenance sociale, ait sous-titré son ouvrage La Distinction de manière délibérément anti-kantienne: Critique sociale du jugement. Pas étonnant que Paul Veyne, l'apôtre du relativisme historique, ait pu soutenir que « la vérité est fille de l'imagination» (1983, p. 123).

II est possible de voir les choses autrement. Dominique Olivier et Serge Provost, on l'a lu, s'insurgent dans leur théorie comme dans leur pratique critique contre le rejet de toute hiérarchie de valeurs. A l'inverse, Ramon Pelinski veut pousser la perspective critique de Kagel jusqu'aux ultimes conséquences du postmodernisme: il n'y a pas de hiérarchie entre les musiques populaires et commerciales, les musiques de tradition orale et les musiques savantes contemporaines (sans parler, sans doute, des musiques classiques).

Qu'en est-il ? Je voudrais simplement mettre le doigt sur certaines contradictions de la position relativiste qui sous-tend toute la démarche "actualiste », dans les trois domaines de l'éthique, de l'épistémologie et de l'esthétique, et qu'on pourrait symboliser par l'oxymore ultime: «La vérité, c'est qu'il n'y a pas de vérité. »

Toutes les cultures se valent ? II faut respecter les styles de chaque culture tout comme leurs traditions et leurs valeurs? D'où vient alors, pour ce qui est du domaine du Beau, que, au sein même de cet ensemble culturel que constituent les Indiens d'Amérique du Nord, les membres de telle ethnie particulière admettent que la musique de telle autre ethnie est de qualité supérieure et qu'il y ait consensus là-dessus lors des rassemblements interethniques? 
Dans le domaine du Vrai : est-il exact que nous ne puissions plus rien dire de vrai sur rien? Si la vérité est fille de l'imagination, "dans ce cas-là ", rétorque Bouveresse, "d'où peut bien venir le concept de réalité qui permet de dire que les chambres à gaz ont existé ou n'ont pas existé dans la réalité, indépendamment de notre imagination ? $(1984$, p. 110$)$. Question gênante, non ?

Et pour ce qui est du Bien, je prendrai un exemple qui fait mal. Le hasard a voulu que j'assiste au festival de cinéma Vues d'Afrique au moment où j'achevais la préparation de ce numéro. Dans une des séances, celle du 3 mai 1995, deux films d'orientation divergente mais consacrés tous deux à l'excision du clitoris ont été juxtaposés. Dans l'un, Dilemme au féminin, réalisé par la Tchadienne Zara Mahamat Yacoub, l'excision était dénoncée dans toute sa barbarie morale, psychologique et physique. L'autre, L'Excision initiatique des jeunes filles gulmances, réalisé par le Nigérian Salifou Yaye, présentait une cérémonie d'excision selon toutes les normes d'un excellent film ethnographique : il établissait des liens entre la cérémonie, les mythes, les catégories de pensée et les traditions, sans jamais porter de jugement de valeur sur la pratique elle-même afin de respecter les normes propres à une "africanité " essentielle. Une journaliste, fidèle à la vulgate féministe qui est trop souvent devenue une nouvelle langue de bois, écrivait dans un avant-papier que le premier film représentait le point de vue féminin, le second, le point de vue masculin (Roberge, 1995). Je ne nierai pas que l'appartenance du réalisateur nigérien au sexe masculin l'ait conduit à évincer du film toute représentation de la douleur féminine (alors que cet aspect est au premier plan du film de la Tchadienne et au premier plan dans le sens propre du terme, puisque l'excision y est crûment montrée, au point que le jour de la projection à laquelle j'ai assisté, une personne s'est évanouie dans la salle). Mais au-delà de l'opposition homme/femme, je crois que la différence d'optique tient essentiellement à une conception du Bien qui, dans un cas, admet l'existence de valeurs humaines universelles et qui, dans l'autre, a recours au respect intangible des valeurs propres à une Culture. Je retiendrai encore de cette expérience la remarque d'une dame blanche de l'auditoire au cours du débat qui suivit la projection : elle souligna le fait que dix ans plus tôt, nous autres Occidentaux aurions hésité à critiquer la cérémonie de l'excision sous le prétexte qu'elle appartenait à une autre culture qu'on ne saurait juger et que, si cette fois-ci, il nous était possible de prendre parti, c'est aussi parce que la critique venait de l'intérieur de la culture africaine...

C'est que les diverses formes de relativisme sont pétries de mauvaise conscience. Parce que le marxisme s'est trompé, il n'est plus permis de prendre parti pour tel ou tel modèle social. Parce que certaines découvertes scientifiques ont des effets pervers terrifiants /l'apocalypse nucléaire, les bouleversements écologiques, l'eugénisme) ou parce que certains états de la recherche scientifique sont remis en question à un stade ultérieur, on prétend 
qu'il n'y a plus de vérités scientifiques. Parce que le modernisme musical s'est accompagné d'exclusivisme esthétique et de pratiques monopolistes (Boulez pour ne pas le nommerl, tout le monde, il est beau, tout le monde, il est gentil.

Et pourtant! La vérification scientifique existe encore. Le caractère cumulatif du savoir aussi. Dans le domaine culturel, Pelinski le reconnaît : "Le discours de la différence culturelle peut inclure le racisme et soutenir des relations asymétriques entre centre et périphérie. " Reconnaissance d'une valeur transcendante, donc, au-delà des spécificités culturelles. Je proposerai un critère: la position que Pelinski critique légitimement chez le Japonais ne peut être défendue parce qu'elle ne peut être érigée en maxime universelle /kantisme pas complètement mort).

Dans le domaine esthétique, les choses sont plus délicates. Comment décider qui a raison dans une évaluation ? Et pourtant, Proust, n'est-ce pas autre chose qu'Henri Troyat? Cézanne autre chose que Maurice Denis? Debussy autre chose que Delius ? Mozart autre chose que Salieri? Wagner autre chose que Meyerbeer? N'y a-t-il pas des œuvres bien faites et d'autres mal fichues? Le postmodernisme aura sans doute eu le mérite historique de réhabiliter l'agréable, mais ce faisant, il redonne ses droits, implicitement, à la distinction entre le sublime, le beau, le médiocre et le nul. Le postmodernisme a légitimement remis à l'honneur la pluralité des jugements de valeur et des jugements critiques. Il est vrai encore que l'esthétique se bat les flancs depuis des siècles pour tenter de définir de manière quelque peu tangible les critères d'évaluation esthétique. Et ce serait sans doute là, sinon la contradiction, du moins la difficulté de la position que je défends: proclamer la nécessité de maintenir le jugement critique, de n'en avoir ni honte ni peur, alors qu'il est extrêmement difficile d'expliciter la hiérarchie des valeurs à laquelle nous faisons tous appel dans notre vie quotidienne, qu'il s'agisse des rapports humains, des décisions politiques ou des productions culturelles.

Mais ce n'est pas parce qu'il est difficile de justifier les jugements de valeur qu'il faut renoncer à l'évaluation esthétique et faire comme si tout s'équivalait. Même s'il n'y a pas de critères universels du Beau - encore que Molino (1990, passim) ait pu suggérer qu'on retrouvait les mêmes traits fondamentaux d'une époque à une autre -, il semble bien, même si le mot n'existe pas dans toutes les langues, que quelque chose comme le sentiment du Beau, tout comme le sentiment amoureux, soit universel dans toutes les cultures humaines. Après tout, nous n'avons pas trop de difficultés à affirmer que c'est pas bien de tuer son voisin, et de reconnaître que 2 plus 2 font 4 . On objectera peutêtre que ce n'est pas du même ordre. Le jugement esthétique prête sans doute moins à conséquence. Encore que la pollution sonore (et «musicale ») qui envahit nos villes (et parfois nos campagnes) me semble tout aussi dommageable que les atteintes à l'environnement. Personne n'empêchera personne de dire, à propos de telle œuvre, qu'il l'aime ou qu'il ne l'aime pas, qu'elle est 
belle, réussie, sublime ou, au contraire, moche et tordue. Comme aurait dit Florent Schmitt, il n'y a pas trente-six sortes de musiques. Il y a la bonne, la mauvaise et celle d'Alain Thibault. Aussi, je ne vois pas ce qui devrait nous empêcher de conjecturer qu'un bon nombre de productions des « musiques actuelles», si elles ont droit à l'existence dans un monde démocratique, n'en sont pas moins destinées, esthétiquement, à sombrer dans les abysses de l'oubli.

On me rétorquera sans doute aussi que, précisément, la musique « actuelle " est faite pour aujourd'hui et que ses adeptes se contrefoutent du jugement de la postérité.

Le débat se ramènerait-il à une différence d'attitudes des protagonistes par rapport au Temps? Le Temps, ce grand faucheur, le Temps, ce grand censeur...

BOULEZ, P. (1995), Points de repère, nouvelle édition de J.J. Nattiez et S. Galaise, Paris, Christian Bourgois éditeur, volume I. Imaginer.

BOURDIEU, P. (1979), La Distinction, Paris, Éditions de Minuit.

BOUVERESSE, J. (1984), Le Philosophe chez les autophages, Paris, Éditions de Minuit.

KANT, E. (1790), Critique de la faculté de juger, trad. Philonenko, Paris, Vrin, 1974.

MOLINO, J. (1990), «Du plaisir au jugement : les problèmes de l'évaluation esthétique », Analyse musicale, $n^{\circ}$ 19, p. 16-26.

ROBERGE, H. (1995), «Deux regards - masculin et féminin - sur l'excision », La Presse, 29 avril 1995.

VEYNE, P. (1983), Les Grecs ontils cru à leurs mythes?, Paris, Seuil. 


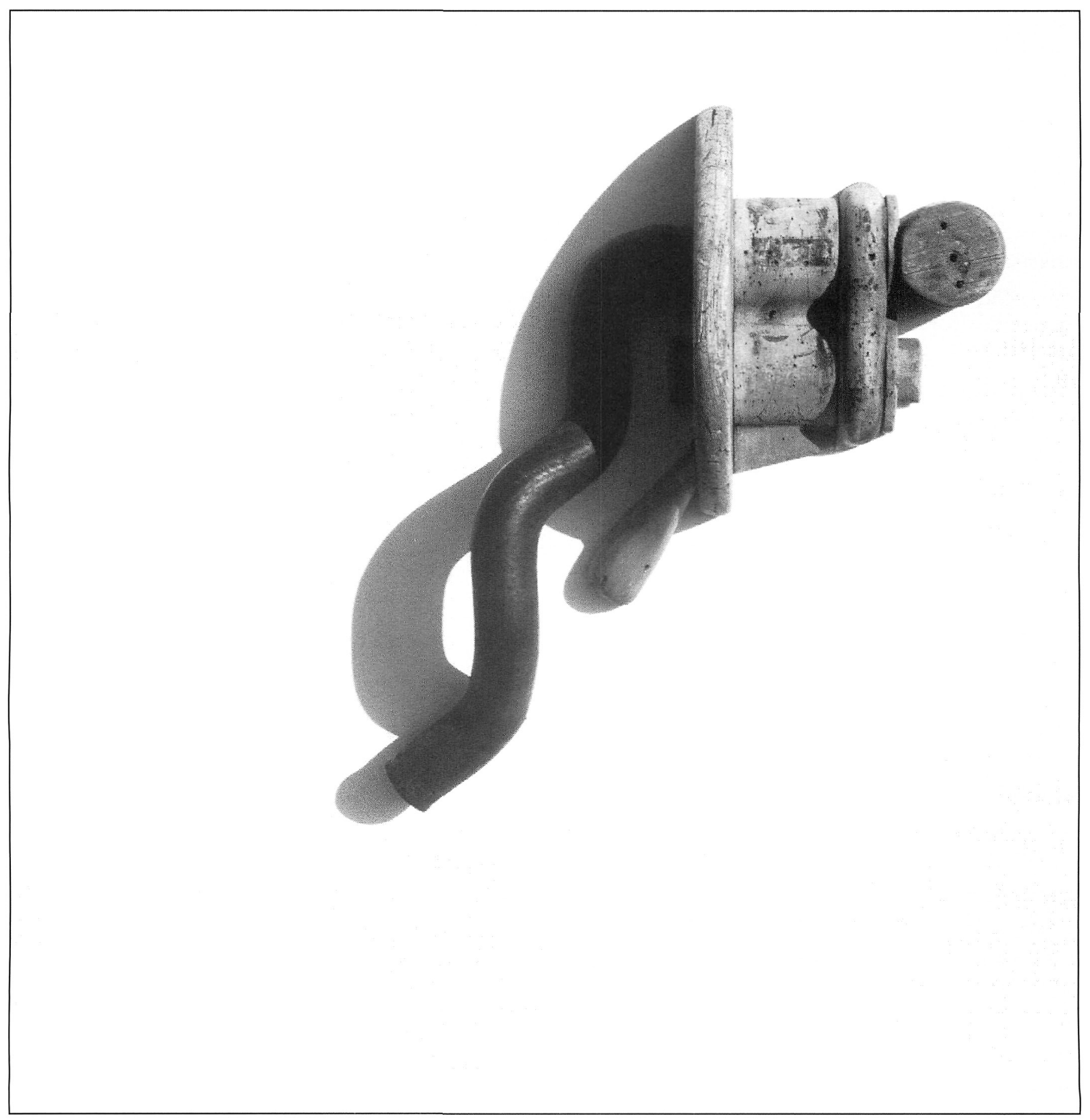

